\title{
Optimization of Constant Power Control of Wind Turbines to Provide Power Reserves
}

\author{
Jan Van de Vyver, Jeroen D. M. De Kooning, Bart Meersman, Tine L. Vandoorn and Lieven Vandevelde
}

\begin{abstract}
In several countries, the wind power penetration increased tremendously in the last years. As the current wind turbines do not participate in frequency control nor reserve provision, this may compromise the proper functioning of the primary control and the provision of power reserves. If no actions are taken, increasing levels of wind penetration may result in serious problems concerning the stable operation of the power system. This paper focuses on the provision of power reserves by wind turbines. For this service, the constant power control strategy is chosen as control strategy, as it gives a constant power output and has the ability to provide power reserves. In this way, the wind turbine behaves more like a conventional power plant. The choice of the power reference value is crucial as it determines whether or not a stable operation of the wind turbine is possible and power reserves can be provided. In this paper, an algorithm is proposed to obtain the range of possible reference values. By means of simulations, the optimal reference value to provide power reserves with a single wind turbine is obtained. Also, reserve provision in a wind farm is investigated. It is shown that the provision of power reserves with wind turbines using the constant power strategy is possible, especially in wind farms.
\end{abstract}

Index Terms-Wind energy, Ancillary services, Power control, Power reserves, Wind farms

\section{INTRODUCTION}

Global environmental concerns have led to the increased use of renewable energy such as solar panels, wind turbines, etc. The great advantage of these renewable energy sources is that they are less polluting than conventional ones and that they are inexhaustible.

One way to capture these abundant sources of energy is the construction of wind turbines. The wind power capacity is growing steadily. Considering this growth, it is likely that wind energy systems will supply a major part of the future electricity generation from renewables. To achieve the EU 2020 targets, a wind power penetration of $15.7 \%$ is expected by 2020 [1]. For comparison, at the end of 2011, an average penetration of $6.3 \%$ was reached in the EU. The highest penetration was reached in Denmark, where almost $26 \%$ of the electricity was produced by wind turbines.

This increase in wind power penetration raises concerns about the secure and reliable operation of the power system. The intermittency of the wind causes a variety of problems. Due to varying wind conditions, fluctuations in the output power of wind turbines arise. To maintain the balance of

J. Van de Vyver, J. D. M. De Kooning, B. Meersman, T. L. Vandoorn and L. Vandevelde are with the Electrical Energy Laboratory (EELAB), Department of Electrical Energy, Systems and Automation (EESA), Ghent University, Sint-Pietersnieuwstraat 41, B-9000 Ghent, Belgium, Telephone: +32 9264 34 42, Fax: +32 926435 82, e-mail: Jan.VandeVyver@UGent.be the power system, the conventional power plants have to be more flexible: they need to operate at part-load levels more often or are even shut down for some time. In addition, these units must also maintain additional reserve to cope with an unexpected drop in the wind speed. This cycling operation of being shut down, started up and operating part-loaded, results in a reduced life cycle and increased costs [2].

Also, difficulties with frequency control may arise when the penetration of wind turbines increases. The variable-speed wind turbines which are predominantly used today have no inertial response and do not participate in frequency control [3]. In the future, it may become mandatory that wind turbines also contribute in the frequency regulation.

However, many of the aforementioned problems can be solved by using an appropriate control strategy for the wind turbines. Most of the wind turbines are equipped with a powerelectronic converter to inject the generated power in the grid. By using different control strategies for this converter, a broad range of ancillary services can be provided by wind turbines. These turbines with a power converter are flexible and have a short response time compared to directly coupled units.

In this paper, the provision of power reserves by wind turbines is investigated. There exist different strategies to control the power output, but the constant power control method is the focus in this work. An optimization algorithm to find the optimal power reference is proposed and the ability to provide power reserves is discussed.

The paper is organized as follows. $\S$ II explains the need for power reserves in the electricity grid. The possibility to use wind turbines for the provision of reserves is discussed. The model of a wind turbine and the different existing strategies to control the power of a wind turbine are listed and discussed in $\S$ III. In $\S$ IV an optimization algorithm to determine the power reference for the constant control strategy is proposed. Some similation results are presented in $\S \mathrm{V}$

\section{Power RESERVES AS AN ANCILlaRy SERVICE}

\section{A. Frequency control and power reserves}

As electricity cannot be stored easily in large quantities, at any given point in time, the amount of electricity produced must equal the amount being consumed. This balance guarantees a stable operation of the electricity grid at a constant frequency of $50 \mathrm{~Hz}$. When there is a sudden drop in electricity production or consumption, frequency deviations occur. To maintain and/or restore the frequency, the output of the generators must be rapidly increased or decreased. 
In the European synchronous electricity grid, the frequency regulation is achieved in three stages: primary, secondary and tertiary control [4].

1) Primary control: Primary control restores the balance between power generation and consumption when a deviation occurs. It is automated and within seconds $(\sim 30 \mathrm{~s})$ the active power output of the generators can be increased or decreased. To achieve this, primary or frequency containment reserves have to be maintained at any time. After the activation of these reserves, the power balance is restored at a frequency deviating from the nominal value.

2) Secondary control: Secondary control is used to restore the grid frequency back to the nominal frequency. Furthermore, the desired power exchange between the different control areas is maintained by this control. Secondary control is only activated in the control area where a power deficit exists and is generally activated automatically. It starts after a few seconds and is usually completed after $15 \mathrm{~min}$. In this case, secondary or frequency restoration reserves are needed. If there still exists a frequency deviation after the activation of these reserves, secondary control gives way to tertiary control.

3) Tertiary control: The main function of the tertiary control is to restore the required level of operating reserves (primary and secondary reserves). Tertiary or replacement reserves are maintained at any time and are activated manually by the transmission system operator (TSO) about 15 min after the initial deviation. Tertiary control copes with persistent control deviations after production outages or long-lasting load changes. The tertiary reserves can be situated in the control area where the power deficit exists or in other areas of the synchronous area.

\section{B. Power reserves provided by wind turbines}

From above, it is clear that power reserves are very important to maintain a balanced electricity system. As long as the wind power penetration is rather low, conventional power plants can provide the necessary amount of reserves. However, when old conventional plants are taken out of service, it is likely that they are not replaced by new ones due to the increased number of wind turbines. This has a negative impact on the available power reserve. To overcome this problem, in the future, wind turbines could provide a part of the needed power reserves. These can be divided into negative and positive reserves [5]:

1) Negative reserves: When there is a decrease in electricity consumption, the generation has to be decreased. The power production of wind turbines can be lowered quite easily by reducing the power coefficient $C_{\mathrm{p}}$. This can be achieved by changing the rotational speed or the pitch angle of the blades. Negative reserves can be provided anytime, but there is a loss of revenue caused by the lower power production.

2) Positive reserves: When there is an increase in electricity consumption, the generation has to be increased. If the turbine is working in the maximum power point, the power production can not be regulated upwards. Providing a positive power reserve at all times implies that the turbine has to be operated sub-optimal, which means a loss of revenue in normal operation.
It is clear that there is no incentive for wind turbine operators to provide power reserves, unless the TSO ensures financial compensation. Considering the current level of renewable generation, providing positive reserves with wind turbines is not profitable [5]. Increasing levels of renewable generation, however, will lead to increased short term balancing costs, according to ENTSO-E [6]. So providing positive reserves may be lucrative in the future. Also, it is likely for frequency response (including positive and negative primary reserves) to become mandatory for large wind farms, which confirms the significance of this research.

\section{GENERAL SYSTEM DESCRIPTION}

In this section, a short overview of the wind turbine model is given. Different power control strategies are presented and the definition of power reserve is introduced.

\section{A. Wind turbine model}

The following equation is known as a good representation of the mechanical power available on the generator shaft of a wind turbine [7]:

$$
P_{\mathrm{t}}=\frac{1}{2} \rho \pi r^{2} v^{3} \cdot C_{\mathrm{p}}(\lambda, \theta)
$$

with $\rho$ the air density, $r$ the rotor radius, $v$ the wind speed at nacelle height parallel to the turbine axis and $C_{\mathrm{p}}$ the power coefficient. The power coefficient is given by [7]:

$$
\begin{gathered}
C_{\mathrm{p}}=0.73\left(\frac{151}{\lambda_{i}}-0.58 \theta-0.002 \theta^{2.14}-13.2\right) e^{\left(-\frac{18.4}{\lambda_{i}}\right)} \\
\lambda_{i}=\frac{1}{\frac{1}{\lambda-0.02 \theta}-\frac{0.003}{\theta^{3}+1}}
\end{gathered}
$$

in which $\theta$ is the blade pitch angle and $\lambda$ is the tip-speed ratio (TSR), defined by:

$$
\lambda=\frac{r \cdot \Omega}{v}
$$

with $\Omega$ the shaft speed of the turbine. In this paper, the pitch angle $\theta$ is considered zero, since the wind turbine is operated below the maximum power and no pitch adjustments are needed. Consequently, the expression for $C_{\mathrm{p}}$ is only a function of the TSR.

\section{B. Power control strategies}

Nowadays, most wind turbines are equipped with a power converter, so they can be operated at a variable shaft speed to increase the energy yield. Since these wind turbines are equipped with a power converter, the power output can be controlled. As the control scheme of these converters differs from type to type, in this paper, it is not elaborated how converters achieve the control of the power delivered by the wind turbine. Instead, it is assumed that the desired reference for the generator power $P_{\text {ref }}$ is perfectly obtained. In Fig. 1 four strategies to determine the power reference $P_{\text {ref }}$ are shown as dashed lines [8], [9]. The solid lines represent the wind power at different wind speeds. 


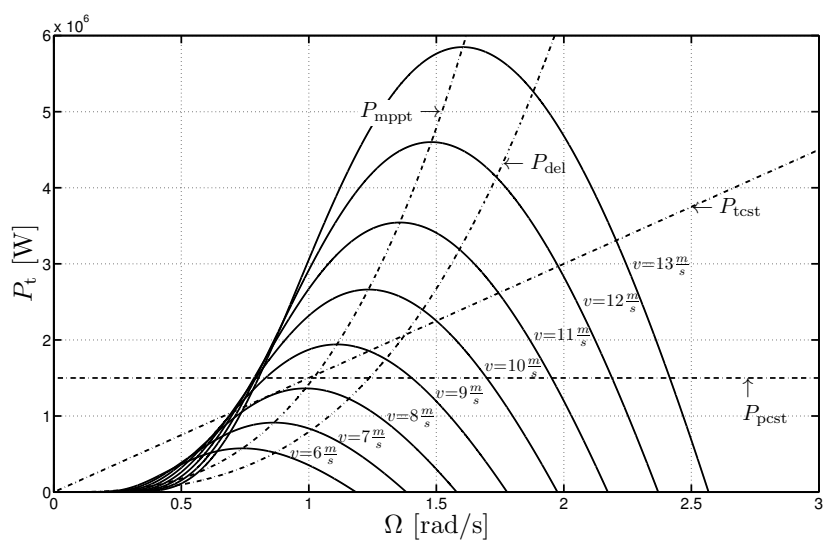

Fig. 1. Illustration of different control strategies. Solid lines: wind power curves, dashed lines: control strategies.

1) Maximum Power Point Tracking $\left(P_{\mathrm{mppt}}\right)$ : For each wind speed $v$, there exists a TSR and consequently a shaft speed $\Omega_{\mathrm{mppt}}$ for which the acquired wind power reaches a maximum. The curve that passes through these maxima, is a cubic function of $\Omega$ :

$$
P_{\mathrm{mppt}}=K_{\mathrm{mppt}} \Omega^{3}
$$

When $P_{\text {mppt }}$ is used as reference power $P_{\text {ref }}$, the maximum power is acquired.

2) Deloaded operation $\left(P_{\mathrm{del}}\right)$ : By shifting the operating point to the right of the maximum power point, the wind turbine is deloaded. This is achieved by shifting the shaft speed from $\Omega_{\text {mppt }}$ to the deloaded speed $\Omega_{\mathrm{del}}$. The deloaded reference power is given by:

$$
P_{\text {del }}=K_{\text {del }} \Omega^{3}
$$

By using $P_{\text {del }}$ as reference power, a power margin, which is a fraction of the maximum available power, is maintained at all times.

3) Constant torque strategy $\left(P_{\text {tcst }}\right)$ : In this case, a constant torque is applied to the generator, resulting in the following reference power:

$$
P_{\mathrm{tcst}}=T_{\mathrm{cst}} \Omega
$$

In Fig. 1. only for wind speeds above $9 \mathrm{~m} / \mathrm{s}$, a stable operating point can be obtained with the constant torque strategy. The constant torque strategy is a special case of the linear slope strategy: $P_{\text {ref }}=P_{0}+T_{\text {cst }} \Omega$.

4) Constant power control $\left(P_{\text {pcst }}\right)$ : In the constant power strategy, the generator is loaded with a constant power $P_{\text {ref }}=P_{\text {pcst }}$ for a certain amount of time (e.g., $600 \mathrm{~s}$ in this paper). The choice of this reference power is difficult, as it depends on the wind speed profile during the time interval of interest. If the reference value is too high, the turbine will slow down too much. Conversely, if the reference is too low, the turbine will accelerate unacceptably. Thus, the better the wind speed profile can be predicted, the better this strategy works. Constant power control will be investigated in this paper. In the next section, a method to obtain the optimal value for $P_{\text {pcst }}$ is proposed.

\section{Reference tracking}

The system dynamics are described by Newton's equation of motion:

$$
J \frac{\mathrm{d} \Omega}{\mathrm{d} t}=T_{\mathrm{t}}-T_{\mathrm{g}}
$$

where $J$ is the total inertia of the system, $T_{\mathrm{t}}$ is the turbine torque and $T_{\mathrm{g}}$ is the generator torque. In this paper, we assume that the converter is able to control the power of the generator $P_{\mathrm{g}}$ perfectly, i.e., $P_{\mathrm{g}}=P_{\text {ref. }}$. Consequently, (8) can also be written as follows:

$$
J \Omega \frac{\mathrm{d} \Omega}{\mathrm{d} t}=P_{\mathrm{t}}-P_{\mathrm{ref}}
$$

The intersection of a solid line (wind power at a given wind speed $v$ ) with a dashed line (chosen reference strategy) in Fig. 1 defines the equilibrium operating point (only intersections to the right of the maximum power point are stable operating points). Usually, the fluctuations in the wind speed are too fast to settle an equilibrium. According to (8), the acceleration and deceleration of the generator make sure the power reference $P_{\text {ref }}$ will be tracked.

\section{Power reserve}

The power reserve $P_{\text {reserve }}$ of a wind turbine can be calculated as [9], [10]:

$$
P_{\text {reserve }}=P_{\text {mppt }}-P_{\mathrm{t}}
$$

\section{CONSTANT POWER CONTROL}

In this section, the constant power control strategy is discussed. An algorithm to find the optimal reference power is proposed.

\section{A. Problem statement}

As already stated, the choice of the reference power is difficult. When the reference power $P_{\text {ref }}$ is chosen, the following conditions must be satisfied:

- The wind speed profile has to be predicted as accurately as possible for the time interval of interest.

- The wind turbine can provide power reserves.

- The wind turbine has a stable operating point for each moment of the time interval.

- The shaft speed $\Omega$ has to be within the speed limits: $\Omega_{\min }<\Omega<\Omega_{\max }$. In this way, the operating range of the wind turbine is respected.

- The turbine power $P_{\mathrm{t}}$ satisfies: $P_{\mathrm{t}}>0$.

All these conditions result in a range of possible power references: $P_{\text {ref }_{\min }}<P_{\text {ref }}<P_{\text {ref }_{\max }}$. The choice of $P_{\text {ref }}$ with respect to these boundaries is determined by the accuracy of the wind speed prediction. If the prediction is accurate, $P_{\text {ref }}$ can be chosen close to these boundaries, otherwise, safety margins should be respected.

Finding the range of reference values $P_{\text {ref }}$ that satisfy all these conditions can be achieved by the algorithm described in the remainder of this section. 


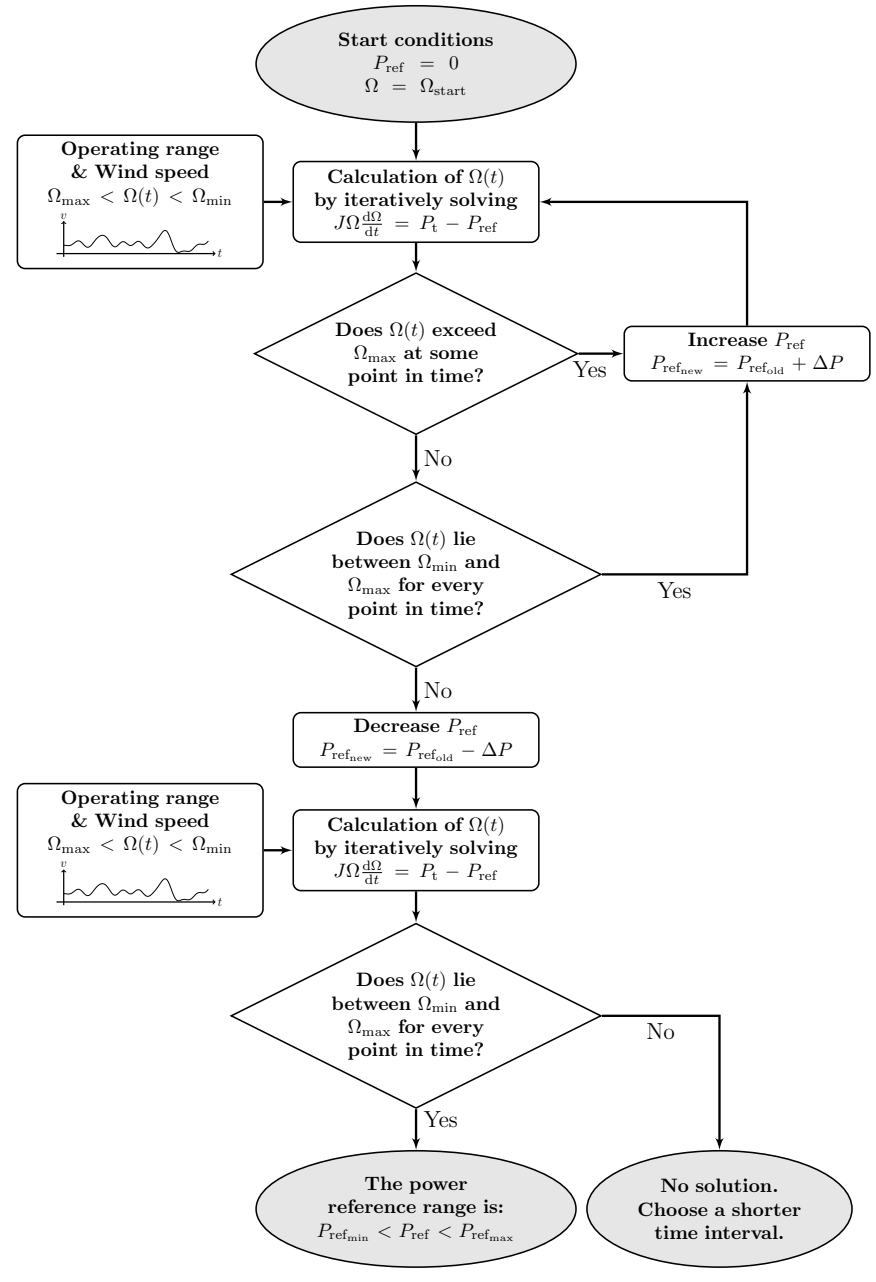

Fig. 2. Schematic overview of the optimization algorithm.

\section{B. Optimization algorithm}

The aim of the optimization algorithm is to find the range of possible reference values $P_{\text {ref }}$ for which the listed conditions are satisfied. In section $\mathrm{V}$, simulations are used to determine which reference power is optimal to provide power reserves.

A schematic overview of the optimization algorithm is shown in Fig. 2 The iterative process starts with:

- $P_{\text {ref }}=0$

- $\Omega_{\text {start }}=\frac{v \lambda_{\mathrm{opt}}}{r}$

with $\lambda_{\text {opt }}$ the tip-speed ratio that maximizes $C_{\mathrm{p}}(\lambda)$. This choice for $\Omega_{\text {start }}$ corresponds to a wind turbine delivering the maximum power before the constant power control is enabled. The (predicted) wind speed $v(t)$ during the time interval of interest is needed to calculate the reference value. Furthermore, the operating range of the wind turbine, $\left[\Omega_{\min }, \Omega_{\max }\right]$, is specified. Then, $\Omega(t)$ is calculated for the given time interval by solving (9). As the initial value of the reference power $P_{\text {ref }}$ is zero, the turbine will accelerate and exceed the upper speed limit $\Omega_{\max }$. Consequently, the reference value $P_{\text {ref }}$ is increased with $\Delta P$ and the calculations are repeated until $\Omega(t)$ is within the operating limits. The choice of $\Delta P$ is a trade-off between speed and accuracy. The higher the value of $\Delta P$, the faster the reference value is found, but the less accurate the
TABLE I

SIMULATION PARAMETERS

\begin{tabular}{|c|c|c||c|c|c|}
\hline Parameter & Value & Unit & Parameter & Value & Unit \\
\hline \hline$P_{\text {rated }}$ & 3.0 & $\mathrm{MW}$ & $\Omega_{\mathrm{nom}}$ & 1.45 & $\mathrm{rad} / \mathrm{s}$ \\
\hline$r$ & 56 & $\mathrm{~m}$ & $\rho$ & 1.225 & $\mathrm{~kg} / \mathrm{m}^{3}$ \\
\hline$J$ & $1.244 \cdot 10^{7}$ & $\mathrm{kgm}^{2}$ & $\Delta P$ & 100.0 & $W$ \\
\hline$\Omega_{\text {min }}$ & 0.85 & $\mathrm{rad} / \mathrm{s}$ & $\Omega_{\max }$ & 2.0 & $\mathrm{rad} / \mathrm{s}$ \\
\hline$C_{\mathrm{popt}}$ & 0.4412 & - & $\lambda_{\mathrm{opt}}$ & 6.908 & - \\
\hline
\end{tabular}

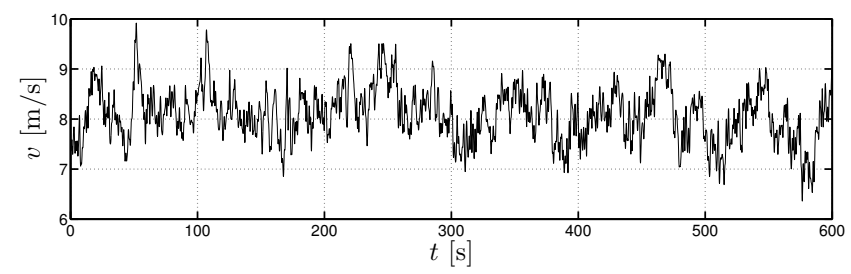

Fig. 3. Simulated wind speed sample.

solution is. The minimum power reference $P_{\text {ref }_{\min }}$ is found as the lowest value for $P_{\text {ref }}$ for which $\Omega(t)>\Omega_{\text {min }}$ and $P_{\mathrm{t}}>0$. To find the maximum power reference $P_{\text {ref }_{\max }}$, the reference value $P_{\text {ref }}$ is further increased with $\Delta P$ until the minimum of $\Omega(t)$ falls below the lower speed limit $\Omega_{\text {min }}$. The iterative process is stopped and the reference value is decreased with $\Delta P$ to give the maximum power reference $P_{\text {ref }_{\max }}$ for which a stable operating point was achieved. Finally, the calculations are done one last time with $P_{\text {ref }_{\max }}$ and it is verified whether $\Omega(t)$ is indeed in the operating range. If this is the case, the power reference value $P_{\text {ref }}$ is obtained. Otherwise, no power reference value can be found for the given wind speed sample $v(t)$ and operating range $\left[\Omega_{\min }, \Omega_{\max }\right]$. In this case, the time interval for which a constant $P_{\text {ref }}$ is maintained has to be shortened until a solution can be found.

In $\S \mathrm{V}$, two reference values in the reference range are used to investigate the reserve capabilities of wind turbines under constant power control. It is assumed that the wind speed can be accurately predicted for the considered time interval, such that no safety margin with respect to the upper and lower power limits $P_{\mathrm{ref}_{\min }}$ and $P_{\mathrm{ref}_{\max }}$ has to be maintained.

\section{Simulation Results}

In this section, some simulation results are summarized. The parameters used in the simulations are listed in Table I

\section{A. Wind turbine with constant power control, $P_{\mathrm{ref}}=P_{\text {ref }_{\max }}$}

The wind speed sample used for these simulations is shown in Fig. 3. A wind model is used to simulate this wind sample. First, the simulations are conducted with the maximum reference value $P_{\text {ref }}=P_{\text {ref }_{\max }}$ obtained with the algorithm developed in section $\mathrm{IV}$. The results of this simulation are shown in Fig. 4

1) Providing power reserves: The maximum reference value $P_{\text {ref }_{\max }}$ corresponding to the wind speed profile of Fig. 3 is $1.1108 \mathrm{MW}$. This corresponds quite well to the mean value of the wind power $P_{\mathrm{t}_{\mathrm{avg}}}=1.1165 \mathrm{MW}$, as may be noted in Fig. 4. This is in line with the expectations, since it indicates the balance between the energy delivered 

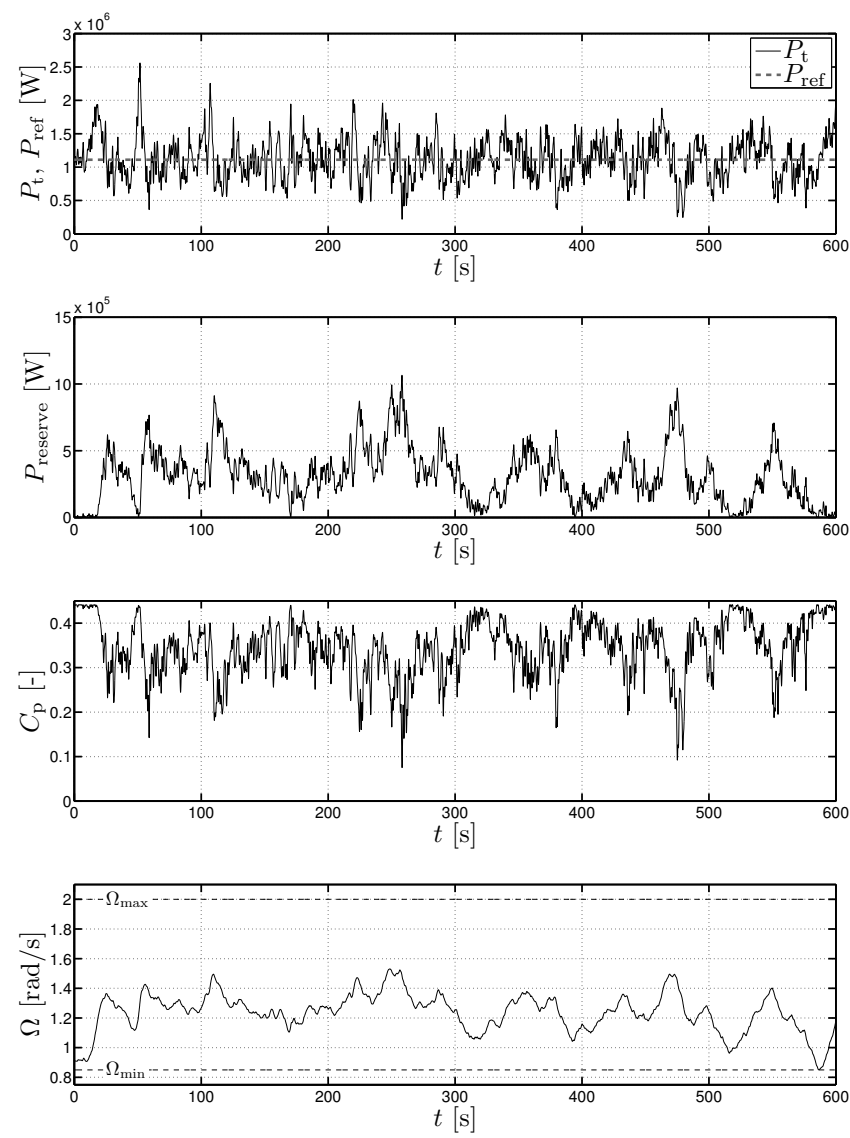

Fig. 4. Simulation with $P_{\text {ref }}=P_{\text {ref }_{\max }}=1.1108 \mathrm{MW}$.

by the turbine and the energy extracted by the generator. As a result, the shaft speed $\Omega$ oscillates around the mean value of $1.24 \mathrm{rad} / \mathrm{s}$. The minimum reference value $P_{\text {ref }_{\max }}$ is $0.8906 \mathrm{MW}$. The simulation shows the capability of the wind turbine to provide power reserves when constant power control is applied. An average power reserve $P_{\text {reserveavg }}$ of about $0.31 \mathrm{MW}$ is available. The maximum power reserve is $1.06 \mathrm{MW}$, while the minimum is approximately $0 \mathrm{MW}$. These minima correspond to the maxima of the $C_{\mathrm{p}}$ curve, which means that the wind turbine already delivers the maximum power. Using $P_{\text {ref }_{\max }}$ as the reference value allows to retain a power reserve during the majority of the time.

2) Comparison with Maximum Power Point Tracking: It is interesting to compare the power output of the constant power strategy and the MPPT strategy [5].

$$
P_{\text {pcst }}=1.1108 \mathrm{MW} \leftrightarrow\left\{\begin{array}{l}
P_{\mathrm{mppt}_{\mathrm{avg}}}=1.417 \mathrm{MW} \\
P_{\mathrm{mppt}_{\min }}=0.878 \mathrm{MW} \\
P_{\mathrm{mppt}_{\max }}=2.08 \mathrm{MW}
\end{array}\right.
$$

With constant power control, the wind turbine generates on average about $22 \%$ less power for the given wind profile compared with MPPT, i.e, $1.1108 \mathrm{MW}$ vs. $1.417 \mathrm{MW}$, which is a disadvantage. However, the use of constant power control makes it possible to maintain power reserves. Moreover, the power output is constant, where it fluctuates highly with the MPPT strategy, as indicated by $P_{\mathrm{mppt}_{\min }}$ and $P_{\mathrm{mppt}_{\max }}$. As expected, the shaft speed $\Omega$ varies more when applying the
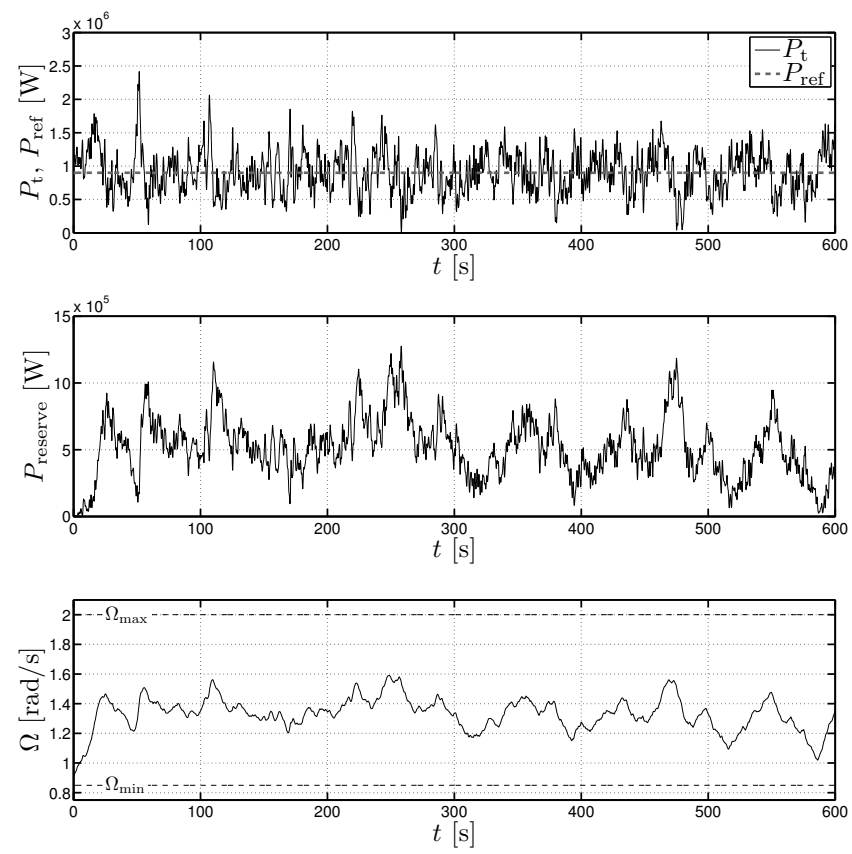

Fig. 5. Simulation with $P_{\text {ref }}=0.9 \mathrm{MW}$.

constant power control:

$$
\begin{aligned}
\Omega_{\mathrm{pcst}_{\min }} & =0.8501 \mathrm{rad} / \mathrm{s} \leftrightarrow \Omega_{\mathrm{mppt}_{\text {min }}}=0.8522 \mathrm{rad} / \mathrm{s} \\
\Omega_{\mathrm{pcst}_{\text {max }}} & =1.5307 \mathrm{rad} / \mathrm{s} \leftrightarrow \Omega_{\mathrm{mppt}_{\text {max }}}=1.1361 \mathrm{rad} / \mathrm{s}
\end{aligned}
$$

In the following, it is examined whether another reference value and/or the aggregation in wind farms could make it possible to maintain a power reserve at any point in time.

\section{B. Wind turbine with constant power control, $P_{\mathrm{ref}}<P_{\mathrm{ref}_{\max }}$}

Again, the wind profile presented in Fig. 3 is used in the simulations. Instead of $P_{\text {ref }_{\max }}$ as the power reference, a lower reference value is used: $P_{\text {ref }}=0.9 \mathrm{MW}$. The results are summarized in Fig. 5

The behavior is quite similar as in the previous case. As expected, the reference power and the average wind power are balanced and the average shaft speed is slightly higher $\Omega_{\mathrm{avg}}=1.33 \mathrm{rad} / \mathrm{s}$. Now, the average generated power is about $37 \%$ lower than with the MPPT strategy.

Considering the ability to provide power reserves, there are some differences. First, the average power reserve is higher: $0.518 \mathrm{MW}$ instead of $0.31 \mathrm{MW}$. Also the maximum power reserve is higher. However, the most interesting difference is found for the minimum power reserve. When neglecting the transient at the start of the simulation (first $20 \mathrm{~s}$ ), the minimum power reserve is $24.5 \mathrm{~kW}$. This indicates that it is possible to maintain a power reserve at any point in time, by lowering the reference value. However, lowering the reference value with more than $0.2 \mathrm{MW}$ results in a minimum power reserve of only $24.5 \mathrm{~kW}$. Consequently, for the wind speed sample of Fig. 3, lowering the reference value strongly affects the average power reserve, but only has a minor effect on the minimum power reserve. When the simulations are repeated with other wind speed profiles, the same conclusions can be 


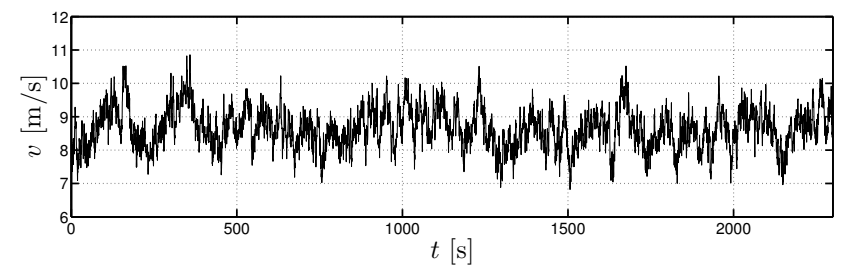

Fig. 6. Wind speed sample in wind farm.

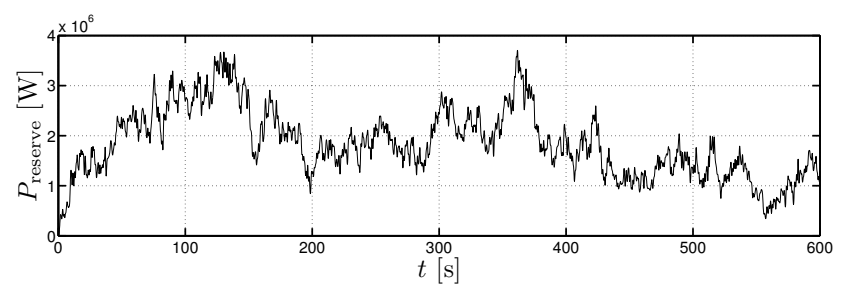

(a) $N=5, P_{\text {tot }}=7.06 \mathrm{MW}$

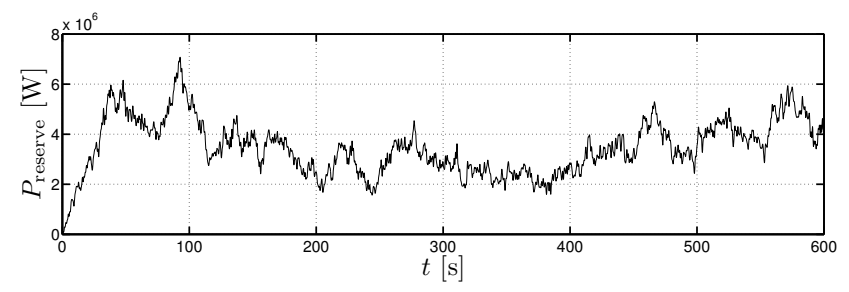

(b) $N=10, P_{\text {tot }}=14.24 \mathrm{MW}$

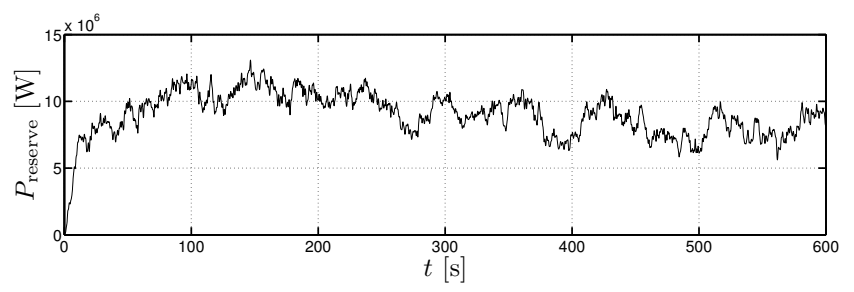

(c) $N=25, P_{\text {tot }}=34.19 \mathrm{MW}$

Fig. 7. Power reserves in wind farms of different size.

drawn. This suggests that lowering the reference value $P_{\text {ref }}$ is not a good way to ensure a minimum power reserve.

\section{Wind farm with constant power control}

The model of the wind farm consists of $N$ randomly positioned wind turbines. It is assumed that no wind turbine falls in the wake of another wind turbine and that each wind turbine experiences the same wind profile, but with some time delays. These delays are associated with the time needed for the wind to transverse the distance between the different wind turbines of the farm [11]. The time delays are simulated by taking a random sample of $600 \mathrm{~s}$ of the wind speed profile in Fig. 6 for each wind turbine. Next, the maximum reference value $P_{\text {ref }_{\max }}$ for each wind turbine is calculated with the presented algorithm. Finally, the power reserve for the complete wind farm is obtained.

In Fig. 7, the power reserve is shown for wind farms of different size. In a wind farm, it is possible to maintain a minimum power reserve at any point in time, even for a small number of wind turbines. The higher the number of wind turbines, the more constant the power reserve becomes. Also, the minimum power reserve increases with increasing number of wind turbines.

\section{CONCLUSIONS}

In this paper, the provision of power reserves by wind turbines with constant power control is investigated. An algorithm to find the optimal reference value for this control strategy is proposed. Then, the power reserves for a single wind turbine and a wind farm are calculated.

The proposed power reference makes it possible to maintain a power reserve during most of the time. Using a lower reference value does not significantly alter the minimum power reference. Aggregation of wind turbines, however, is the best way to provide a minimum power reserve all the time.

This work shows that wind turbines with constant power control can be used to provide power reserves. Furthermore, the power output is constant, which simplifies the balancing by the TSO. The lower energy yield and the need for a good prediction of the wind speed can be mentioned as disadvantages of this control method.

\section{ACKNOWLEDGMENT}

The research of J. D. M. De Kooning is funded by the Special Research Fund (BOF) of Ghent University (Belgium). The work of T. Vandoorn is financially supported by the FWOVlaanderen (Research Foundation - Flanders, Belgium). The research has partly been funded by the Interuniversity Attraction Poles programme IAP-VII-02, initiated by the Belgian Science Policy Office.

\section{REFERENCES}

[1] The European Wind Energy Association, "Pure power - wind energy targets for 2020 and 2030," 2011. http://www.ewea.org/publications/ reports/

[2] N. Troy, E. Denny, and M. O'Malley, "Base-load cycling on a system with significant wind penetration," IEEE Transactions on Power Systems, vol. 25, pp. 1088-1097, May 2010.

[3] J. M. Mauricio, A. Marano, A. Gomez-Exposito, and J. L. M. Ramos, "Frequency regulation contribution through variable-speed wind energy conversion systems," IEEE Transactions on Power Systems, vol. 24, pp. 173-180, Feb. 2009.

[4] ENTSO-E, "Survey on ancillary services procurement and electricity balancing market design," 2012. https://www.entsoe.eu

[5] T. Kapetanovic, B. Buchholz, and V. Buehner, "Provision of ancillary services by dispersed generation and demand side response - needs, barriers and solutions," Elektrotechnik \& Informationstechnik, vol. 125, pp. 452-459, Dec. 2008.

[6] ENTSO-E, "Developing balancing systems to facilitate the achievement of renewable energy goals," 2011. https://www.entsoe.eu

[7] J. G. Slootweg, S. W. H. de Haan, H. Polinder and W. L. Kling, "General model for representing variable speed wind turbines in power system dynamics simulations," IEEE Transactions on Power Systems, vol. 18, pp. 144-151, Feb. 2003.

[8] C. Luo, H. Banakar, B. Shen, and B.-T. Ooi, "Strategies to smooth wind power fluctuations of wind turbine generator," IEEE Transactions on Energy Conversion, vol. 22, pp. 341-349, June 2007.

[9] K. Vidyanandan and N. Senroy, "Primary frequency regulation by deloaded wind turbines using variable droop," IEEE Transactions on Power Systems, vol. 28, pp. 837-846, May 2013.

[10] L.-R. Chang-Chien and Y.-C. Yin, "Strategies for operating wind power in a similar manner of conventional power plant," IEEE Transactions on Energy Conversion, vol. 24, pp. 926-934, Dec. 2009.

[11] P. Li, H. Banakar, P.-K. Keung, H. G. Far, and B.-T. Ooi, "Macromodel of spatial smoothing in wind farms," IEEE Transactions on Energy Conversion, vol. 22, pp. 119-128, Mar. 2007. 